\title{
THE ROLE OF TEACHER IMMEDIACY AS A MOTIVATIONAL FACTOR IN STUDENT LEARNING
}

\author{
Tran Huu Ai \\ Luu Hoang Giang \\ Van Hien University, Ho-Chi Minh,Vietnam
}

This research uses the structural equation modeling (SEM) analysis to find the correlation between the variables of Teaching effectiveness, Teacher behavior and affective learning and that of Student motivation in learning, Teacher immediacy and learning outcomes and Student learning outcomes. A model is built so that to confirm that teachers produce the intermediate influence and also motivate the learning outcomes, cognitive ones especially. Data obtained here in the course of survey proves to be consistent with our initial model. The results show that the immediate teachers' function is to be the means of increasing students' motivation to learn, and that such motivation, in its turn, increases students' cognitive abilities.

Keywords: teachers' immediacy; student motivation; teaching effectiveness; teacher behavior

\section{Introduction}

This research reconsiders the impact of teachers' immediacy on learning outcomes from the activities in the classroom. Mehrabian $(1969,1981)$ viewed immediacy as a set of behaviors creating a perception of physical or psychological closeness between communicators. Immediacy behavior bridges the psychological distance between the two sides. Mehrabian's original emphasis was on non-verbal immediacy, but later on this author also developed a taxonomy of verbal components as well (Wiener and Mehrabian, 1968). While there seems to be little controversy about the measurement or incidence of behavioral

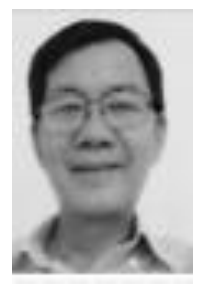

\section{Ai Tran Huu}

$\mathrm{PhD}$, lecturer of Faculty of Economics, Van Hien University, Ho Chi Minh City, Vietnam

Research interests - markets of agricultural products, SMEs functioning and government support, organic food markets, ecological economics, environmental issues of economic development and corporate social responsibility

Published more than 50 papers in International journals, member of editorial board of International journals

\section{E-mail: aith@vhu.edu.vn}

\section{Luu Hoang Giang}

Faculty of Economics, Van Hien University, Ho Chi Minh City, Vietnam

Research interests -corporate social responsibility, modern educational practices, innovative teaching technologies 
non-verbal elements, validity of verbal operations remains to be a rather controversial issue (Hess and Smythe, 2001).

In today's schools globalwide, students are not given enough opportunities to explore, interact with peers, or use their own creativity to learn. The focus is often on testing and text results, while activities and learning experiences that are likely to excite students are often being excluded as such (Carey, 2008). When failing to take into account students' motivation and engagement in the learning process, teachers also fail to engage students who are most likely to drop out of school as such. This may explain why national assessments of student performance during the past decade tends to reveal quite moderate improvements in terms of basic skills and show students' poor performances in tests that require critical thinking and problem-solving skills, namely, formulating hypotheses, making inferences, and drawing conclusions (Riley, 1999). Several studies have investigated the relationships between teacher immediacy and student learning. However, most of them only involved university students only. For example, Richmond et al. (1990) investigated students' perceptions of non-verbal teacher behaviors associated with cognitive learning.

\section{Literature review}

Applications of the notion "immediacy" in educational settings introduced the idea that a teacher, through the use of certain cues, could reduce the perceived distance between instructor and learners and thereby influence classroom outcomes in general, especially student learning results. The classroom provides a setting in which communication acts transpire. An important element of the instructional setting is interaction between the instructor and the students. Various demographic factors have been shown to contribute to the nature of this interaction in classrooms. Researchers have used meta-analyses to examine classroom variables such as gender and race (Cooper and Allen, 1998) of both students and instructors. The research use of the structural equation modeling (SEM) in examining immediacy is justifiable as a means of evaluating a relatively simple set of behaviors that a teacher can modify. Le Blanc (1997) mentioned appropriate curriculum materials, competent and dedicated teachers when discussing the importance of motivating students to learn in relation to the working conditions that are necessary for effective teaching and learning to occur.

Christopher (1995) proposed that teachers' immediacy behavior impacts students' motivation to study, which in turn impacts student learning. Christopher (1995) examined the students' traits that are motivating them to study. They found that teacher immediacy (both verbal and non-verbal) was positively associated with students' motivation to study, with state motivation being more highly related to the immediacy than trait motivation. Therefore, they concluded that immediacy had to first modify state motivation to study in order to impact learning. The same author also found the non-verbal immediacy to be positively associated with state motivation to study, affective learning, and perceived cognitive learning.

\section{Student learning outcomes (SLO)}

Student learning outcomes should be understood, first of all, as observable or measurable behaviors that the students are expected to demonstrate as a result of taking a course. Student learning outcome (or SLO) is also a statement that specifies in detail what 


\section{THE ROLE OF TEACHER IMMEDIACY}

students will know, be able to do or be able to demonstrate once they complete or participate in a program/activity/course/project. These outcomes are usually expressed as knowledge, skills, attitudes or values. SLOs specify an action by the student that must be observed, measurable and/or demonstrated. Ultimately, SLOs are expected to provide students with a roadmap of where exactly various learning opportunities are available throughout the course of learning/teaching.

The first level of learning outcomes can be labeled as "receiving". It refers to learners' readiness to focus their attention on a particular issue. In order to advance further, a learner must be aware of it, attend something or become attached to something within the learning environment. When "receiving," learners are discovering new concepts from their environment and are showing a willingness to learn more details about them.

The second level, "responding," refers to showing some sort of commitment to an idea by reacting to or actively responding to the information that has been received. Learning outcomes at this level may cover mostly the responses of acquiescence/compliance (the student reads assigned materials), the willingness to provide a response (the student shows his/her interest).

At the third level, "valuing," affective learning occurs when a learner shows definitive involvement in or a commitment to a particular object, phenomenon, or behavior. Valuing is based on the internalization of a set of specific values or attitudes, where clues to these values are expressed in the learner's stable overt behavior.

\section{Teaching effectiveness (TE)}

According to McCroskey et al. (2002), teaching effectiveness does not only lie in subject content and knowledge, it also addresses how effective the communication is for the audience. Moore and Kuol (2007) reported the following: "Throughout most of the commentaries on what constitutes good teaching, an ability and a willingness to communicate effectively appears to be the most commonly cited factor ... both by teacher and student groups". Teaching effectiveness is important because effective teaching helps student learning. It has become even more important as the emphasis on quality in higher education has increased. Effective teaching does not occur by chance. Effective teachers become better when they themselves change the instructional practices of teaching. Thus, the first hypotheses can be formulated as follows:

H1: Teaching effectiveness has a positive effect on student learning outcomes.

\section{Teacher immediacy behavior and affective learning (TIBAL)}

Affective learning has been described as learning from focusing on a positive or negative attitude a student develops towards the subject or the teacher (Christopher, 1990). Student affective learning is comprised of student attitudes that include concerns about the course, its content, and the instructor. Gigliotti (1987) reported that students have expectations about instructor communication behaviors such as the use of examples, organization of the course overall, the ability to answer questions in a simple and understandable manner, the clarity of new ideas, and the instructor's speaking ability etc. Gigliotti (1987) suggested that if these communication behavior expectations are met, then students experience a greater desire to learn. The second hypotheses can be formulated as follows:

H2: Teacher immediacy behaviors have a positive effect on student learning outcomes. 


\section{Student motivation in learning (SML)}

In the area of learning, motivation is recognized as a necessity due to its support of a lifelong interest in learning (National Research Council, 2000). Student motivation in learning is of particular interest to researchers because of its relationship to student attitude, cognitive engagement, and academic achievement (Evans, 2004). Theo Broad (2004) indicated that the intricate task of stimulating students' desire to learn is one of the most significant challenges for educators in the 21st century. Many educators are frustrated and want to give up because they do not understand why students are unmotivated and do not want to learn at all. The third hypotheses can be formulated as follows:

H3: Student motivation in learning has a positive effect on student learning outcomes.

\section{Teacher immediacy and learning outcomes (TILO)}

The efficacy of non-verbal immediacy behavior is based on a reinforcement paradigm underlying the attraction theory (Mehrabian, 1990). Stated simply, persons approach those stimuli that provide rewards and are passive or avoid those stimuli that are not rewarding or on the opposite - are punishing them. The immediacy behavior that a teacher is displaying in communicative acts and interactions with students, therefore, can be seen as rewarding. It follows that these rewarding behaviors may serve as reinforcement increasing affective, cognitive, and behavioral learning of students. Increasing the willingness of students to approach and engage in educational tasks is critical for the learning process overall. The fourth hypotheses can be formulated as follows:

H4: Teacher immediacy has a positive effect on student learning outcomes.

\section{Research model}

The proposed model acknowledges the previous research examining the relationship between immediacy and students' affect or motivation to learn (Christopher and Gorham, 1995). Consistent with Mehrabian's (1981) original conceptualization of immediacy, the impact of teacher immediacy is determined by students' perception and interpretation of such behavior. The contribution of the communicator in this setting involves the examination of what role of the instructor contributes to the dynamic relationship between the teacher and the learner. Higher levels of immediacy would contribute to a positive reinforcement that creates a motivation for the students to interact with the teacher and also creates the sense of reward or positive valence. The likely result of high immediacy is the increased desire of the students to perform the role of the active learner in the classroom.

\section{Methodology}

\section{Data analysis}

This study uses the exploratory factor analysis (EFA) and confirmatory factor analyses (CFA) along with the structural equation models (SEM) to test the hypotheses formulated above. SEM is clear and testable, thus, competing models can be analyzed, synthesized and understood and, their effect, whether direct, indirect or both, can be investigated (Schumacker and Lomax, 2010).

Reliability and validity. The internal consistency of the questionnaire was determined through calculating the Cronbach's alpha coefficients using stepwise reliability analysis. 


\section{THE ROLE OF TEACHER IMMEDIACY}

Internally inconsistent items were sequentially deleted, therefore, maximizing the scale's reliability at 0.70 (Sekaran and Bougie, 2010: 325). The Cronbach coefficient alphas were at the acceptable level (exceeding 0.7), thus implying that measurement instruments were fairly reliable.

\section{Description of the survey sample}

The sample of 127 students and 24 teachers was drawn, using the systematic sampling method. The respondents who fully completed their questionnaires during the group administration process were taken as the sample. Finally, the valid samples were analyzed.

\section{Confirmatory factor analysis (CFA)}

The correlation coefficient between the components with accompanying standard deviation (Tab. 1) shows us these coefficients are less than 1 (with statistical significance). Therefore, the components: Teaching Effectiveness (TE), Student motivation in learning (SML), Teacher Immediacy Behaviors and Affective Learning (TIBAL), Teacher immediacy and learning outcomes (TILO) are worth distinguishing.

Table 1 - Results of testing the components (Source: authors' calculations)

\begin{tabular}{llllccc}
\hline \multicolumn{2}{c}{ Correlation } & & R & S.E. & C.R. & P-value \\
\hline TE & $<-->$ & TIBAL & .944 & .155 & 6.071 & $* * *$ \\
TE & $<-->$ & TILO & .738 & .134 & 5.487 & $* * *$ \\
SML & $<-->$ & TIBAL & .750 & .149 & 5.030 & $* * *$ \\
SML & $<-->$ & TILO & .688 & .135 & 5.087 & $* * *$ \\
TIBAL & $<-->$ & TILO & 1.006 & .164 & 6.135 & $* * *$ \\
TE & $<-->$ & SML & .563 & .122 & 4.616 & $* * *$ \\
\hline
\end{tabular}

The linear structural analysis shows that the model's chi-squared statistics is 120.030 with 71 degrees of freedom and the value of $p=0000$. Chi-squared relative degrees of freedom according to $\mathrm{Cmin} / \mathrm{df}$ was $1.691(<2)$. Other indicators demonstrated the following results: $\mathrm{TLI}=0.949(>0.9), \mathrm{GFI}=0.923(>0.9), \mathrm{CFI}=0.949(>0.9)$ and $\mathrm{RMSEA}=0.059$ $(<0.08)$. Therefore, this model fits the data collected. This also allows us drawing individual judgments about the direction of the observed variables. As for the values' convergence, the standardized weights of the scales are $>0.5$ with statistical significance being $p<0.05$, so the scale achieved the convergence value. 


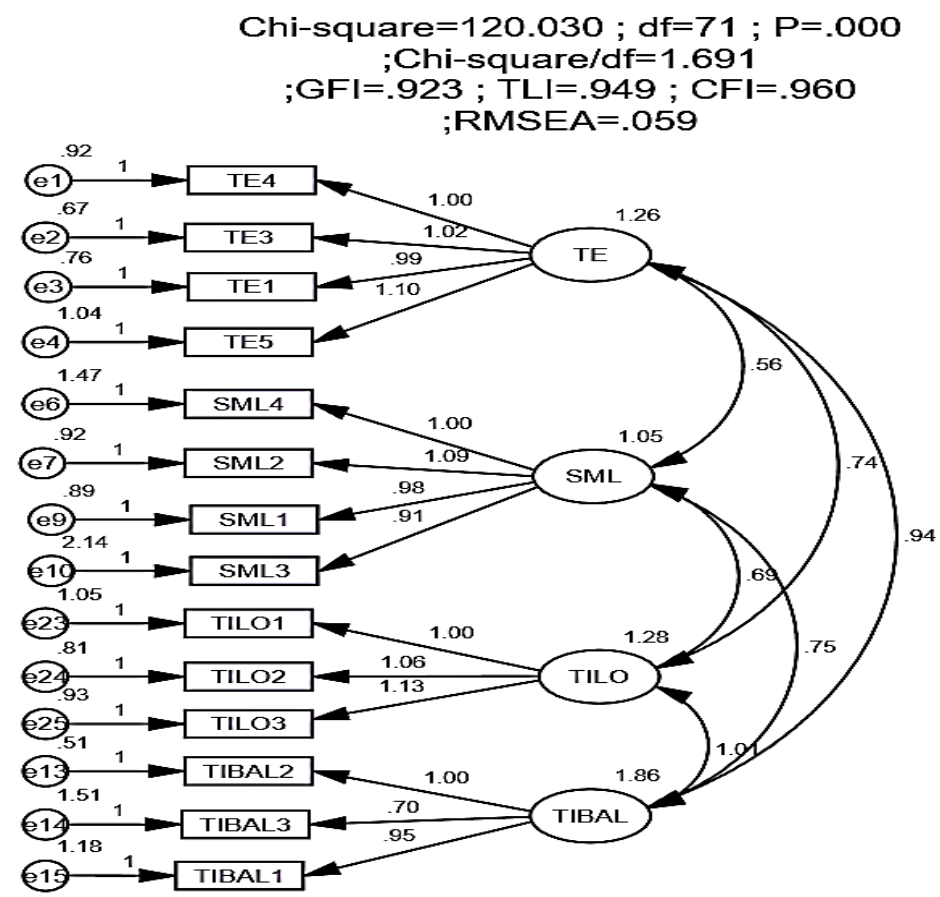

Figure 1- Results of the CFA scale for student learning outcomes

(Source: authors' own construction)

\section{Structural Equation Modeling Results}

This table shows the results of the suitability test for both structure - teacher immediacy behaviors and student learning outcomes. Structural modeling here results in two sets of data. The appropriate model indices, Chi-square (X2), were used in this study to examine the relationships among the variables in the model (Hair et al., 2006). AMOS output as presented in Tab. 2 shows that the models are equipped with good data, thus, the proposed model is appropriate in explaining the relationship between the variables.

Table 2 - Results of the AMOS analyses for the resultant models, author's synthesis

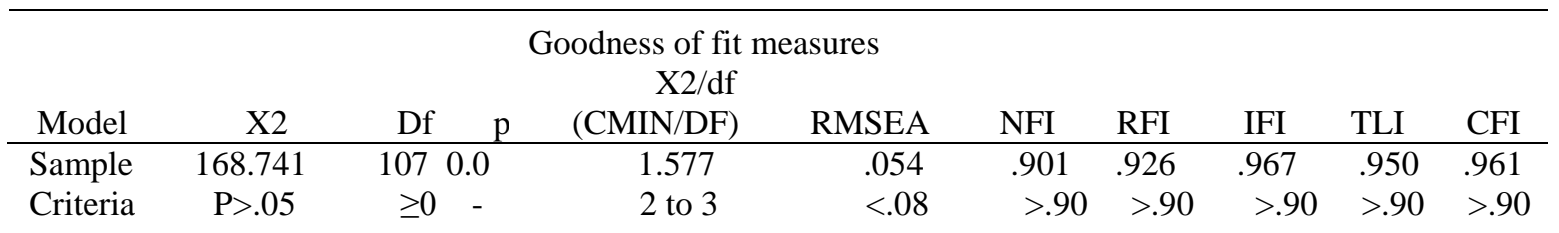

Legend: $\mathrm{X}^{2}=$ Chi-square test, $\mathrm{Df}=$ Degrees of freedom, RMSEA = Root mean square error of approximation, NFI = Normed Fit Index, RFI = Relative Fit Index, IFI = Incremental Fit Index, TLI = Tucker-Lewis Index, CFI = Comparative Fit Index.

The results show that this model's chi-squared statistics are 168.741 with 107 degrees of freedom $(\mathrm{p}=0.000)$. Chi-squared relative degrees of freedom according to CMIN/DF was $1.577(<2)$. Other indicators are: GLI $=0.914(>0.9), \mathrm{TLI}=0.950(>0.9), \mathrm{CFI}=0.961(>0.9)$ and RMSEA $=0.054(<0.08)$. 


\section{THE ROLE OF TEACHER IMMEDIACY}

Therefore, this model achieved the compatibility with the data already collected. The factors include: Teaching effectiveness (TE) $(\mathrm{ES}=0.273 ; \mathrm{P}=0.012)$; Student motivation in learning $(\mathrm{SML})(\mathrm{ES}=0.481 ; \mathrm{P}=0.000)$, Teacher immediacy and learning outcomes (TILO) $(\mathrm{ES}=0.188 ; \mathrm{P}=0.022)$ and Teacher immediacy behaviors and affective learning (TIBAL) $(\mathrm{ES}=0.125 ; \quad \mathrm{P}=0.000)$, they all had the $\mathrm{P}$ values $<0.05$ and the estimated values are normalized.

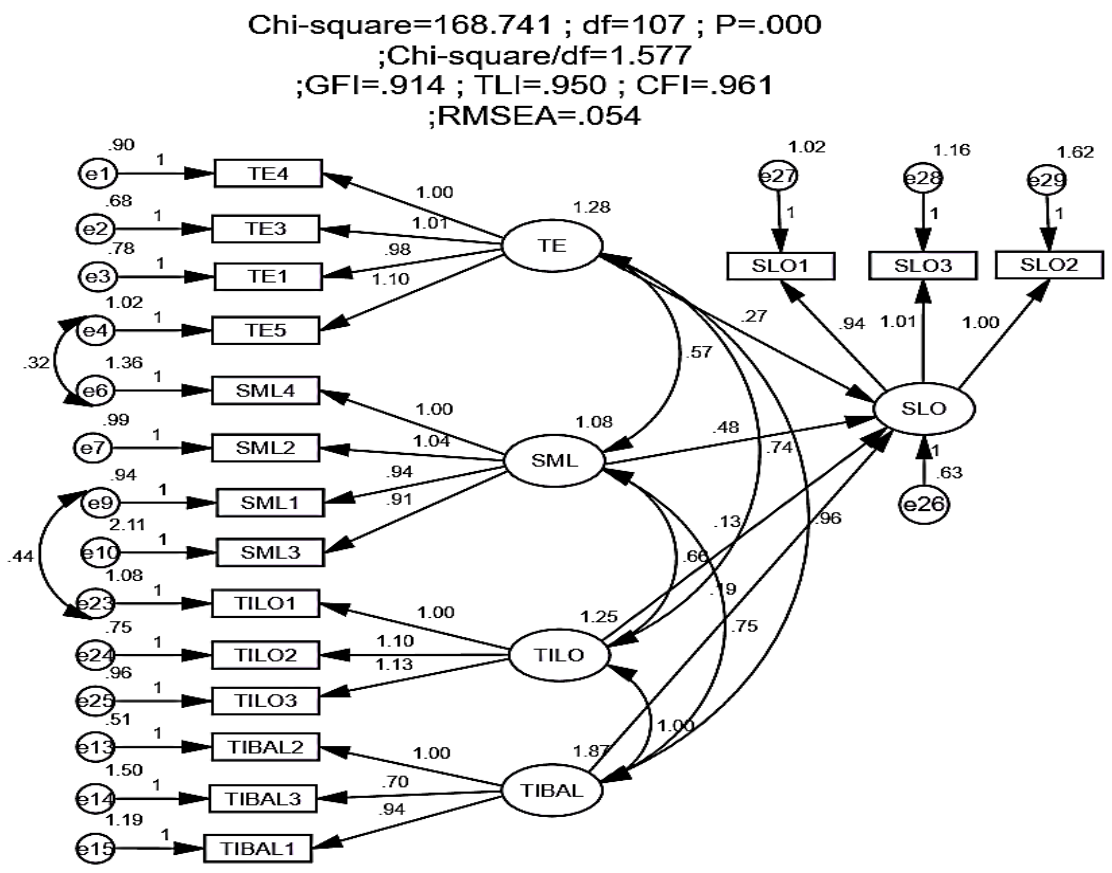

Figure 2 - SEM Results

(Source: authors' own construction)

Table 3 - Results of estimating the causal relationships between the elements of student learning outcomes

(Source: author's own calcuations)

\begin{tabular}{cccccccc}
\hline & Relations & & Estimate & S.E. & C.R. & P & Label \\
\hline SLO & $<---$ & TE & .273 & .108 & 2.515 & .012 & Yes \\
SLO & $<--$ & SML & .481 & .124 & 3.873 & $* * *$ & Yes \\
SLO & $<--$ & TELO & .125 & .121 & 1.036 & .000 & Yes \\
SLO & $<--$ & TIBAL & .188 & .101 & 1.868 & .022 & Yes \\
\hline
\end{tabular}

Testing the reliability of estimates by Bootstrap

Bootstrap method is often used to test the model estimates. In our case, the model has the pattern repeat of $\mathrm{N}=1000$. The estimation results from 1000 samples are averaged together with the deviations and are presented in Table 4. CR has a very small absolute value, it can be said that the deviation is very small, while not statistically significant at the $95 \%$ confidence level. Thus, we can conclude that the model estimates can be trusted. 
Therefore, we can conclude that the model estimates for the student learning outcomes can be trusted. Teaching effectiveness $\left(\mathrm{H}_{1}\right)$, Student motivation in learning $\left(\mathrm{H}_{2}\right)$, Teacher immediacy and learning outcomes $\left(\mathrm{H}_{3}\right)$, Teacher immediacy behaviors and affective learning $\left(\mathrm{H}_{4}\right)$, all have positive relationship with the student learning outcomes. Thus, all our hypotheses are accepted theoretically.

Table 4 - Results estimated by bootstrap with $\mathrm{N}=1000$

(Source: Authors' own synthesis)

\begin{tabular}{|c|c|c|c|c|c|c|c|c|c|}
\hline & & \multicolumn{3}{|c|}{ Estimated standard } & \multicolumn{5}{|c|}{ Estimated bootstrap with } \\
\hline \multicolumn{2}{|c|}{ Parameter } & & imate & SE & SE-SE & Mean & Bias & SE-Bias & CR \\
\hline SLO & $<--$ & TE & .273 & .118 & .003 & .273 & .001 & .004 & 0.25 \\
\hline SLO & $<---$ & SML & .481 & .185 & .004 & .478 & -.003 & .006 & -0.5 \\
\hline SLO & $<---$ & TELO & .125 & .127 & .003 & .108 & -.017 & .004 & -4.25 \\
\hline SLO & $<---$ & TIBAL & .188 & .102 & .002 & .190 & .002 & .003 & 0.67 \\
\hline
\end{tabular}

\section{Conclusion}

\section{Results and Discussion}

The research outcome presented above is in line with quite many previous studies since it continues to justify researchers' attention on teacher immediacy as an aspect of classroom behavior that can improve learning outcomes by means of increasing student motivation. Motivation of students is a highly important parameter for many countries globalwide, since college dropout rates are often exceeding 50\% (Ehrenberg and Zhang, 2004). And the actions that instructors can take to reduce this rate are a significant factor. The impact on education may not be as obvious as what has been learned in a particular class and in what amount. If the motivation to finish a certain course/program is improved - this will eventually lead to higher graduation rates overall. A dominant model that predicts the rates of dropping out in college education (Tinto, 1975) focuses on the sense of connection that students have (or have not) in relation to the academic environment.

Our findings show a positive effect on the students' motivation to learn of the student learning outcomes $(\mathrm{ES}=0.481, \mathrm{p}=0.000<0.05$ ). This result is similar to those presented in most of previous studies (Comstock et al., 1995). The study results also show that the teacher immediate behaviors are affecting the student learning outcomes.

The findings show that the positive effect of teaching effectiveness on student learning outcomes is actually the weakest here $(\mathrm{ES}=0.125, \mathrm{p}=0.000<0.05)$. According to the results we have obtained here, understanding the positive effects by the college/university administrators, professors, and teaching assistants ultimately benefits the students. Immediacy increases the likelihood of student affect for the subject, recall of the material learned, enrollment in similar courses, institutional integration, and degree completion at the end.

Finally, the results show a positive relationship between Teacher immediacy behaviors and affective learning and Teacher immediacy and learning outcomes with the student learning outcomes $(\mathrm{ES}=0.188, \mathrm{p}=0.022<0.05)$ and $(\mathrm{ES}=0.125, \mathrm{p}=0.000<0.05)$ accordingly. This result is very much the same to the research found in Luke LeFebvre et al. (2014). The presence of a positive interpersonal relationship between teachers and students 


\section{THE ROLE OF TEACHER IMMEDIACY}

influences the development of favorable attitudes towards the learning situation overall (Richmond et al., 1987) and towards the whole institution too (Sweet, 1986). Increased instructor immediacy also boosts student-teacher communication and interaction. If students communicate more actively with their teachers, then they will surely get more information they need (Richmond and McCroskey, 2000).

\section{Suggestions for further research}

The key limitation of our research is that the sample was restricted to one school in HCM city only. Therefore, additional studies about teachers' effectiveness in learning conducted for various school groups would be needed so that to determine which factors of student motivation are most appropriate for learning and also so that to promote student learning outcomes as a way of making the whole process of learning more sustainable. Further research could be also carried out on a much larger sample in different schools in other localities and various educational settings so that to validate the findings of this study and also to see whether the measures developed here are statistically reliable and valid across different settings (other education levels, other cities/region/country).

\section{References:}

Carey, G. (2008). High stakes standardized testing. Retrieved from http://www.associatedcontent.com/article/846217/high_stakes_standardized_testing.html?cat= 9

Christopher, D. \& Gorham, J. (1995). A test / retest analysis of student motivation, teacher immediacy, and perceived sources of motivation and demotivation in college classes. Communication Education, 44. 292-306.

Comstock, J., Rowell, E. \& Bowers, J. (1995). Food for thought: Teacher nonverbal immediacy, student learning, and curvilinearity. Communication Education, 44. 251-266.

Cooper, E. \& Allen, M. (1998). A meta-analytic examination of the impact of student race classroom interaction. Communication Research Reports, 15. 151-161.

Ehrenberg, R.G. \& Zhang, L. (2004, December). Do tenured and tenure-track faculty matter? Paper of the Cornell Higher Education Research Institute supported by a grant from the Andrew H. Mellon Foundation and Atlantic Philanthropies, Cornell University.

Evans, C. (2004). Learning with inquiring minds. The Science Teacher, 71. 27-30.

Hair, A. JF., Black, W.C., Babin, B.J., Anderson, R.E. \& Tatham, R.I. (2006). Multivariate Data Analysis.

Gigliotti, R. J. (1987). Are they getting what they expect? Teaching Sociology, 15. 365-375.

Hess, J. \& Smythe, M. J. (2001). Is teacher immediacy actually related to student cognitive learning? Communication Studies, 52. 197-219.

LeFebvre, L. \& Allen, M. (2014). Teacher immediacy and student learning: An examination of lecture/laboratory and self-contained course sections Journal of the Scholarship of Teaching and Learning, 14 (2). 29-45.

McCroskey, J. C., Richmond, V. P. \& McCroskey, L. L. (2002). The role of communication in instruction: The first three decades. In: B. Y. Gayle, R. W. Press, N. Burrell, and M. Allen, Classroom Communication and Instructional Processes: Advances Through Meta-Analysis. Mahwah, NJ: Lawrence Erlbaum.

Mehrabian, A. (1969). Some referents and measures of nonverbal behavior. Behavioral Research Methods and Instrumentation, 1. 203-207.

Mehrabian, A. (1981). Silent messages: Implicit communication of emotion and attitude.

Belmont, CA: Wadsworth Publishing Company, Inc. 
Moore, S. \& Kuol, N. (2007). Matters of the heart: Exploring the emotional dimensions

of educational experience in recollected accounts of excellent teaching. International Journal for Academic Development, 12 (2). 87-98.

Richmond, V. P., Gorham, J. S. \& McCroskey, J. C. (1987). The relationship between selected immediacy behaviors and cognitive learning. In M. McLaughlin (Ed.), Communication yearbook 10. Beverly Hills, CA: Sage.

Richmond, V. \& McCroskey, J. (2000). Nonverbal Behavior in Interpersonal Relations. Boston: Allyn and Bacon.

Richmond, V. P. (1990). Communication in the classroom: Power and motivation. Communication Education, 39. 181-195.

Riley, C. (1999). Evidential understanding, period, knowledge and the development of literacy: A practical approach to 'Layers of Inference' for key stage 3. Teaching History, 97. 6-12.

Schumacker, R. E. \& Lomax, R. G. (2010). A beginner's guide to structural equation modeling (3rd ed.). New York: Routledge.

Sekaran, U. \& Bougie, R. (2010). Research methods for business: A skill-building approach (5th ed.). Haddington: John Wiley and Sons.

Tinto, V. (1975). Dropout from higher education: A theoretical synthesis of recent research. Review of Education Research, 45. 89-125.

Wiener, M. \& Mehrabian, A. (1968). Language within language: Immediacy, a channel of verbal communication. New York: Appleton-Century-Crofts.

Paper submitted

Paper accepted for publishing

Paper published online
27 June 2018

19 August 2018

30 November 2018 